\title{
Preparation of composite adsorbent with high performance of heat and mass transfer
}

\author{
BU XianBiao*, LU ZhenNeng \& WANG LingBao \\ Key Laboratory of Renewable Energy and Gas Hydrate, Guangzhou Institute of Energy Conversion, Chinese Academy of Sciences, Guangzhou \\ 510640, China
}

Received January 27, 2013; accepted May 21, 2013

\begin{abstract}
To develop a new composite adsorbent with high performance, fir sawdust and $\mathrm{CaCl}_{2}$ are selected as raw materials. The mass transfer is enhanced by carbonizing and activating the sawdust and heat transfer is enhanced by adding expanded graphite into the adsorbent. The effect of the preparation temperature and the expanded graphite content on the adsorption performance is investigated. The results show that the new adsorbent exhibits a high adsorption performance due to its high porosity, uniform distribution and high content of $\mathrm{CaCl}_{2}$ and high thermal conductivity. Also, the experimental results indicate that the rate of ammonia adsorption on the adsorbent depends on the expanded graphite content and the carbonization and activation temperature. The adsorbent prepared at $500^{\circ} \mathrm{C}$ and with the expanded graphite content of $30 \%$ has the best performance in terms of the adsorption refrigeration, which adsorbs ammonia as high as $0.37 \mathrm{~g} \mathrm{~g}^{-1}$ at $10 \mathrm{~min}$.
\end{abstract}

composite adsorbent, carbonization activation, enhanced heat transfer, enhanced mass transfer, adsorption refrigeration

Citation: $\quad$ Bu X B, Lu Z N, Wang L B. Preparation of composite adsorbent with high performance of heat and mass transfer. Chin Sci Bull, 2013, 58: 3709-3714, doi: 10.1007/s11434-013-5994-9

Adsorption refrigeration systems powered by low grade thermal energy such as waste heat or solar energy have drawn considerable attention due to the benefits of simple control, silent operation with no vibrations and lower operation costs $[1,2]$. However, the widespread acceptance of the adsorption systems is hindered by its relatively poor performances and large size due to limited properties of adsorbents [3].

The adsorption capacity of physical adsorbents can hardly exceed 30wt\% [4]. The adsorption capacity of chemical adsorbents (calcium chloride, strontium chloride, barium chloride, etc.) is rather high, however, the problem of swelling and agglomeration always occurs during the adsorption and desorption process, which results in a poor heat and mass transfer and prevents putting the single chemical adsorbents into practice [5]. In order to overcome these disadvantages, several works have been carried out [6-10]. Aristov and his coworkers, Wang and Zhang developed a

*Corresponding author (email: buxb@ms.giec.ac.cn) new composite adsorbent by confining chemical adsorbents $\left(\mathrm{CaCl}_{2}, \mathrm{BaCl}_{2}, \mathrm{MgCl}_{2}\right.$, etc.) into the open pores of a porous host matrix (silica gel, alumina, active carbon, etc.) [11-15]. All their studies showed that the composite adsorbent has a higher adsorption capacity and can solve the problem of swelling and agglomeration of chemical adsorbents [16-19]. However, the content of chemical adsorbents in the composite adsorbent prepared by impregnating a porous host matrix with chemical adsorbents is only $30 \%-40 \%$, leading to a great reduction of the cycle uptake per unit mass of composite adsorbent. In addition, to improve the thermal conductivity, the consolidation of adsorbents is often needed, which weakens the mass transfer due to some channels of the adsorbents being blocked. That is to say, there is a contrast between enhanced mass transfer and enhanced heat transfer.

To overcome the shortage of low content of chemical adsorbents in the composite adsorbents and solve the contrast between enhanced mass transfer and enhanced heat transfer, a new method for the preparation of adsorbent is 
developed. $\mathrm{CaCl}_{2}$ and sawdust are selected as raw materials. $\mathrm{CaCl}_{2}$ is first impregnated into the sawdust, the mixture of $\mathrm{CaCl}_{2}$ and sawdust is subsequently carbonized and activated at a fixed temperature to prepare a new composite adsorbent with high porosity [20]. Next, the conductivity material, such as expanded graphite, is added into the composite adsorbent to enhance the heat transfer. As a result, the composite adsorbent has not only a developed pore structure but also a high thermal conductivity. The experimental results show that the new adsorbent exhibits a high adsorption performance due to its high porosity, uniform distribution and high content of $\mathrm{CaCl}_{2}$, and solve the contrast between enhanced mass transfer and enhanced heat transfer. Here we first present the carbonization and activation method for the preparation of a new composite adsorbent, and then investigate the effect of the carbonization and activation temperature and the expanded graphite content on the performance of the new adsorbent.

\section{Experimental}

\subsection{Sample preparation}

The fir sawdust with size of 20-30 meshes and pure calcium chloride powder are selected as raw materials for the preparation of composite adsorbents. The raw materials are dried at $120^{\circ} \mathrm{C}$ for $24 \mathrm{~h}$. Next, the sawdust is immerged into $\mathrm{CaCl}_{2}$ aqueous solutions with mass concentration of $50 \%$ for $24 \mathrm{~h}$. The mixture of sawdust and $\mathrm{CaCl}_{2}$ is then filtered out from the solution and dried at $120^{\circ} \mathrm{C}$ in a vacuum drier until the mixture weight remains constant. Note that after drying, the content of $\mathrm{CaCl}_{2}$ in the mixture is $68.21 \mathrm{wt} \%$. After that, the mixture is placed into a tube furnace and adsorbent is then prepared based on a combination of carbonization and activation process in a single step. $\mathrm{CO}_{2}$ is used as the activation agent. In the one-stage process the mixture is heated under $\mathrm{N}_{2}$ at a rate of $10^{\circ} \mathrm{C} \mathrm{min}{ }^{-1}$ to a specified temperature in the range of $400-700^{\circ} \mathrm{C}$ and kept at the same temperature under $\mathrm{CO}_{2}$ for a specified time to yield adsorbent. Both the carbonization time and activation time are $1 \mathrm{~h}$. Four samples, S1-S4, are prepared according to the difference of carbonization and activation temperature $(400$, 500,600 and $700^{\circ} \mathrm{C}$ ). The mixture without being carbonized and activated is denoted as S0. The detailed information of the adsorbent prepared by carbonization and activation method is shown in Table 1.

Table 1 Characteristics of adsorbents prepared under different temperatures

\begin{tabular}{ccccc}
\hline Sample & $\begin{array}{c}\text { Burn- } \\
\text { off }(\%)\end{array}$ & $\begin{array}{c}\text { Content of } \\
\mathrm{CaCl}_{2}(\%)\end{array}$ & $\begin{array}{c}\text { Crystallinity } \\
\text { of } \mathrm{CaCl}_{2}(\%)\end{array}$ & $\begin{array}{c}\text { Average pore } \\
\text { diameter }(\mathrm{nm})\end{array}$ \\
\hline S1 & 23.77 & 73.79 & 38.72 & 18.2 \\
S2 & 48.24 & 80.57 & 44.54 & 33.9 \\
S3 & 52.96 & 82.03 & 52.03 & 44.1 \\
S4 & 56.80 & 83.25 & 54.89 & 20.5 \\
\hline
\end{tabular}

To improve the thermal conductivity of the adsorbent, the expanded graphite with size of 80 meshes and expansion degree of 300 is added into the adsorbent. Five samples, S10-S50, are prepared according to the difference of the content of expanded graphite. Sample S10 consists of $10 \%$ (in mass) expanded graphite and $90 \% \mathrm{~S} 2$, and sample S20 consists of $20 \%$ expanded graphite and $80 \%$ S2, and so on.

\subsection{Performance test}

The adsorption performance is evaluated by the ammonia sorption on the adsorbent with the evaporation temperature of $-5^{\circ} \mathrm{C}$ and condensation temperature of $40^{\circ} \mathrm{C}$. The schematic diagram of the experimental set-up is shown in Figure 1 , where valve 5 is used to regulate the pressure in buffer tank 3 and deflate, and valve 8 is connected to the vacuum pump. The adsorber is a flange connection which makes the replacement of the sample very convenient. The volumes of the buffer tank and adsorber are 23091.58 and $80.99 \mathrm{~cm}^{3}$, respectively. The temperatures of water are measured by thermocouples with precisions of $\pm 0.1^{\circ} \mathrm{C}$, and the system pressure is measured with two calibrated pressure transducers with ranges of $0-1 \mathrm{MPa}$ and precisions of $0.1 \% \mathrm{FS}$.

The experimental procedure is as follows:

(1) The composite adsorbent is first dried at $120^{\circ} \mathrm{C}$ for $24 \mathrm{~h}$ in an oven to make sure that all water vapor is eliminated from the sample;

(2) Fill $10 \mathrm{~g}$ composite adsorbents into the adsorber and then connect the adsorber with the buffer tank;

(3) Create a vacuum in the adsorber for $1 \mathrm{~h}$ at $90^{\circ} \mathrm{C}$ through the valve 8;

(4) Adjust the thermostatic water baths 11 and 2 at $40^{\circ} \mathrm{C}$ and $25^{\circ} \mathrm{C}$, respectively;

(5) Through the valves 4 and 5, adjust the pressure in the buffer tank 3 to be $354.76 \mathrm{kPa}$, which is the saturation pressure of $\mathrm{NH}_{3}$ at $-5^{\circ} \mathrm{C}$;

(6) Open the valve 7 , the adsorption starts. During the process, the pressures and temperatures of the adsorber 10 and buffer tank 3 are recorded by a computer.

The $\mathrm{NH}_{3}$ uptake, $w$, on the composite adsorbent is calculated by the following equation:

$$
w=\frac{\left(p_{0}-p_{\mathrm{eq}}\right) V_{1}}{R T_{1}}-\frac{p_{\mathrm{eq}}\left(V_{2}-V_{\mathrm{ad}}\right)}{R T_{2}},
$$

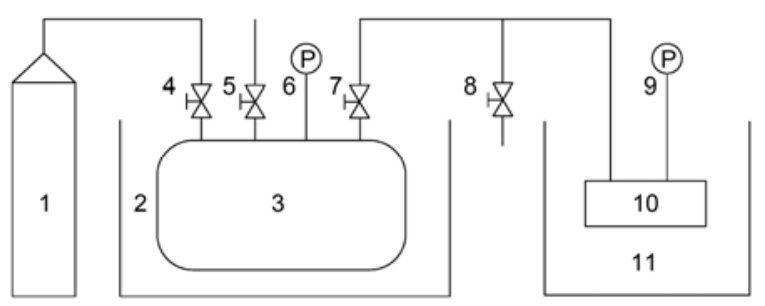

Figure 1 Experimental set-up (1 is a high-pressure container of $\mathrm{NH}_{3}, 2$ and 11 are constant temperature water baths, 3 is a buffer tank of $\mathrm{NH}_{3}, 4,5$, 7 and 8 are valves, 6 and 9 are pressure sensors, and 10 is an adsorber). 
where $T_{1}$ and $T_{2}$ are the temperatures of the buffer tank and adsorber (K), respectively, $V_{1}$ and $V_{2}$ are the volume of the buffer tank (including the volumes associated with pipes and valves) and adsorber, respectively, $V_{\text {ad }}$ is the volume occupied by the adsorbents; $p_{0}$ is the initial pressure in the buffer tank $(\mathrm{Pa}), p_{\text {eq }}$ is the equilibrium pressure of reaction $(\mathrm{Pa})$, and $R$ is the gas constant of $\mathrm{NH}_{3}\left(\mathrm{~J} \mathrm{~kg}^{-1} \mathrm{~K}^{-1}\right)$.

The sample morphology is observed using a scanning electron microscope (SEM) (model: HITACHI S-4800). The elements distribution in the adsorbent is analyzed by HORIBA EMAX energy spectrometer. To investigate the crystallinity of $\mathrm{CaCl}_{2}$ in the adsorbent, X-ray diffraction analysis is carried out according to an XRD apparatus (PANalytical X' pert Pro MPD). The thermal conductivity of the adsorbent is measured by non-steady state plating method.

The schematic diagram of the thermal conductivity experimental set-up is shown in Figure 2. The heat flux is measured by a voltmeter and an ammeter with precisions of $0.2 \% R$, respectively. The temperatures of the adsorbent are measured by thermocouples with precisions of $\pm 0.1^{\circ} \mathrm{C}$.

The experimental procedure is as follows:

(1) Put the composites of adsorbent and expanded graphite into a mould with the length $\times$ width $\times$ height of $100 \mathrm{~mm} \times$ $100 \mathrm{~mm} \times 10 \mathrm{~mm}$;

(2) Turn the switch on and record the number readings of voltmeter, ammeter and thermocouples;

(3) End the experiment when the temperature difference between the upper and lowest surface of adsorbent does not change;

(4) Calculate the thermal conductivity according to the following formula.

$$
\lambda=\frac{U I \delta}{4 A \Delta t},
$$

where $\lambda, U, I, \delta, A$ and $\Delta t$ are the thermal conductivity, heating voltage, heating electric current, thickness of adsorbent, area of adsorbent and temperature difference, respectively.

\section{Results and discussion}

\subsection{Effect of the preparation temperature on the adsorption performance}

The burn-off is defined as follows:

$$
\text { Burn-off }=\frac{w_{1}-w_{2}}{w_{1} \times\left(1-n_{1}\right)} \times 100
$$

where $w_{1}$ is the weight of sample before carbonization and activation, $w_{2}$ is the weight of sample after carbonization and activation, and $n_{1}$ is the content of $\mathrm{CaCl}_{2}$ in the sample before carbonization and activation, $n_{1}=68.21 \%$.

It can be seen from Table 1 that the burn-off increases monotonically with the rise of the carbonization and activation temperature due to the removal of volatile elements during the carbonization and activation step. While increasing carbonization and activation temperature also leads to the increase of the content of $\mathrm{CaCl}_{2}$ in the sample from $73.79 \%$ at $400^{\circ} \mathrm{C}$ to $83.25 \%$ at $700^{\circ} \mathrm{C}$. In [13], the content of $\mathrm{CaCl}_{2}$ in the sample prepared by confined $\mathrm{CaCl}_{2}$ into the pore of silica gel is only $34.85 \%$. Meanwhile, the crystallinity of $\mathrm{CaCl}_{2}$ also increases from $38.72 \%$ to $54.89 \%$ with increasing carbonization and activation temperature from 400 to $700^{\circ} \mathrm{C}$. Average pore diameters in the samples increase first and then decrease with the increase of carbonization and activation temperature.

Figure 3(a) and (b) depict the SEM micrographs of samples S0 and S2. The SEM micrograph shows that compared with sample S0, sample S2 has a developed pore structure

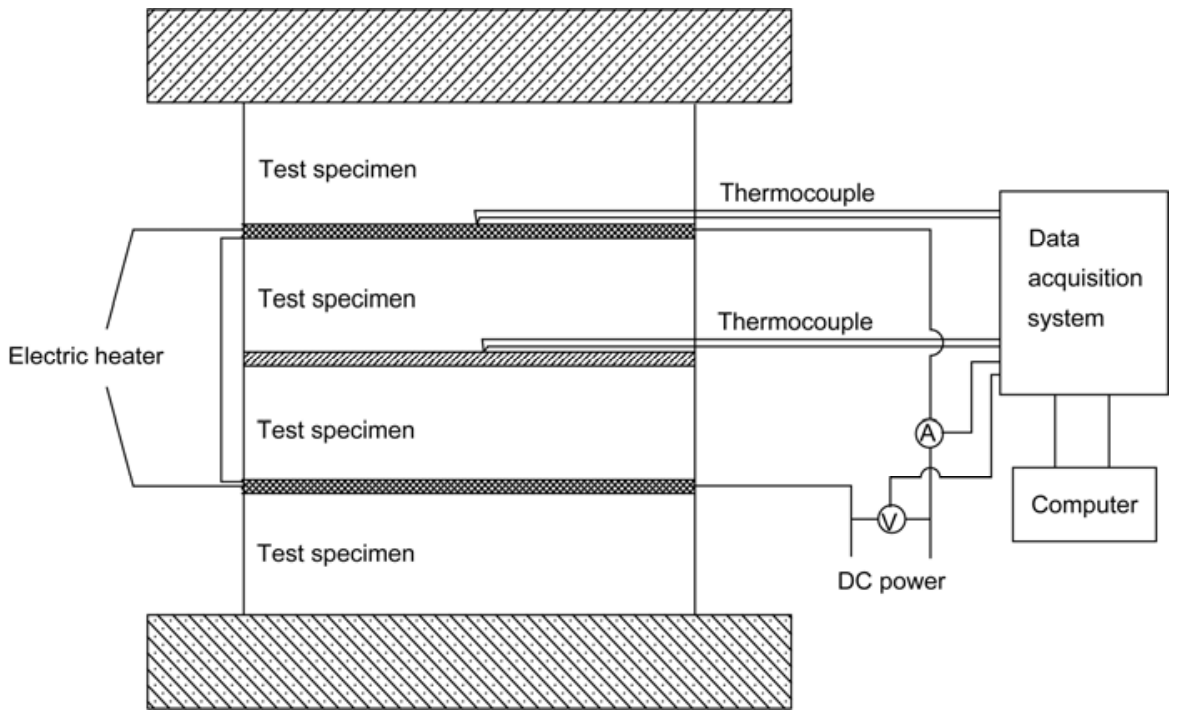

Figure 2 Schematic diagram of the non-steady state plating method. 


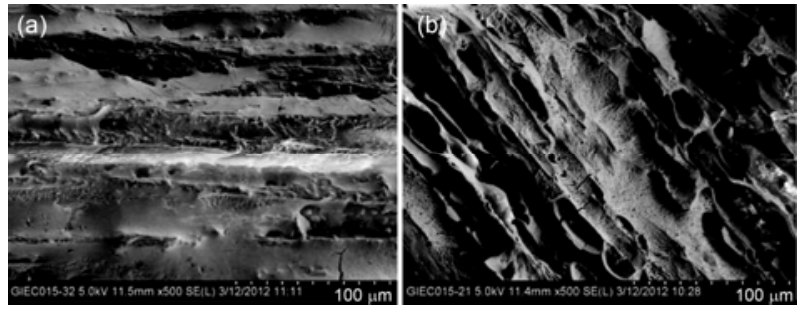

Figure 3 SEM image of samples (a) S0 and (b) S2.

due to carbonization and activation, resulting in the enhancement of mass transfer.

It is obvious from Figure 4(a)-(c) that the elements of C, $\mathrm{Cl}$ and $\mathrm{Ca}$ disperse uniformly in sample $\mathrm{S} 2$, even though there is a partial crystallinity.

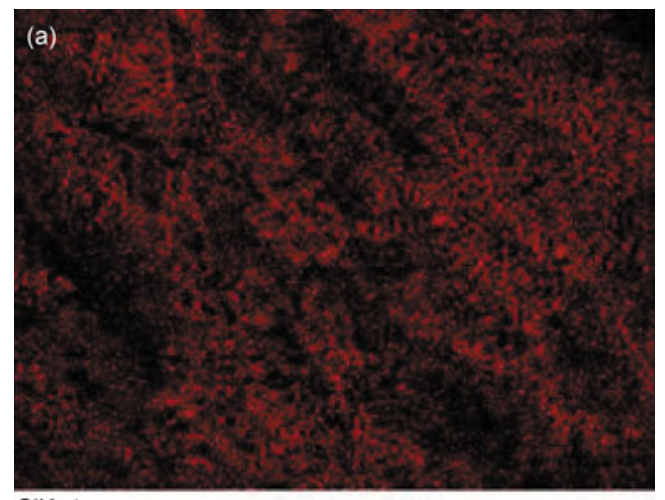

ClKa1
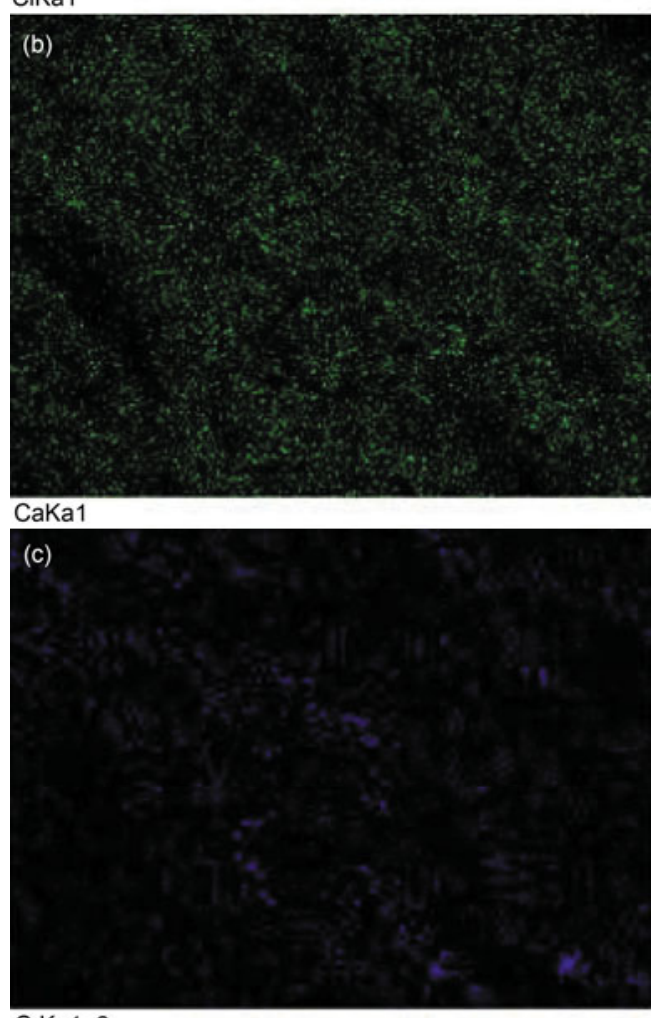

C Ka1_2

Figure 4 The distribution of element in sample S2. (a) Cl; (b) Ca; (c) C.
From Figures 3 and 4, it can be concluded that during the process of ammonia adsorption and desorption on the adsorbent, the rich pore in the adsorbent provides the space for $\mathrm{CaCl}_{2}$ swelling, even though the swelling occurs, the agglomeration does not take place due to the rich pore and uniform dispersion of $\mathrm{CaCl}_{2}$.

Figure 5(a) and (b) describe the adsorption amount of four samples as a function of adsorption time under the conditions of adsorption temperature $40^{\circ} \mathrm{C}$, desorption temperature $90^{\circ} \mathrm{C}$ and evaporation temperature $-5^{\circ} \mathrm{C}$. By observing the profiles in Figure 5(a), it can be noticed that the amount of adsorbed ammonia on the adsorbent at $4 \mathrm{~h}$ increases with the increase of the carbonization and activation temperature. In other words, the amount of adsorbed ammonia on the adsorbent at $4 \mathrm{~h}$ increases with the increase of $\mathrm{CaCl}_{2}$ content. The adsorption amounts are respectively $0.76,0.82,0.83$ and $0.84 \mathrm{~g} \mathrm{~g}^{-1}$ at adsorption time of $4 \mathrm{~h}$ for samples S1, S2, S3 and S4. However, when the adsorption time is less than $1 \mathrm{~h}$, the adsorption amount first increases and then decreases with the increase of carbonization and activation temperature for four samples, as shown in Figure 5(b). Sample S2 prepared at the carbonization and activation temperature of $500^{\circ} \mathrm{C}$ has the best adsorption performance, which adsorbs as high as $0.63 \mathrm{~g}$ ammonia per $\mathrm{g}$ adsorbent at
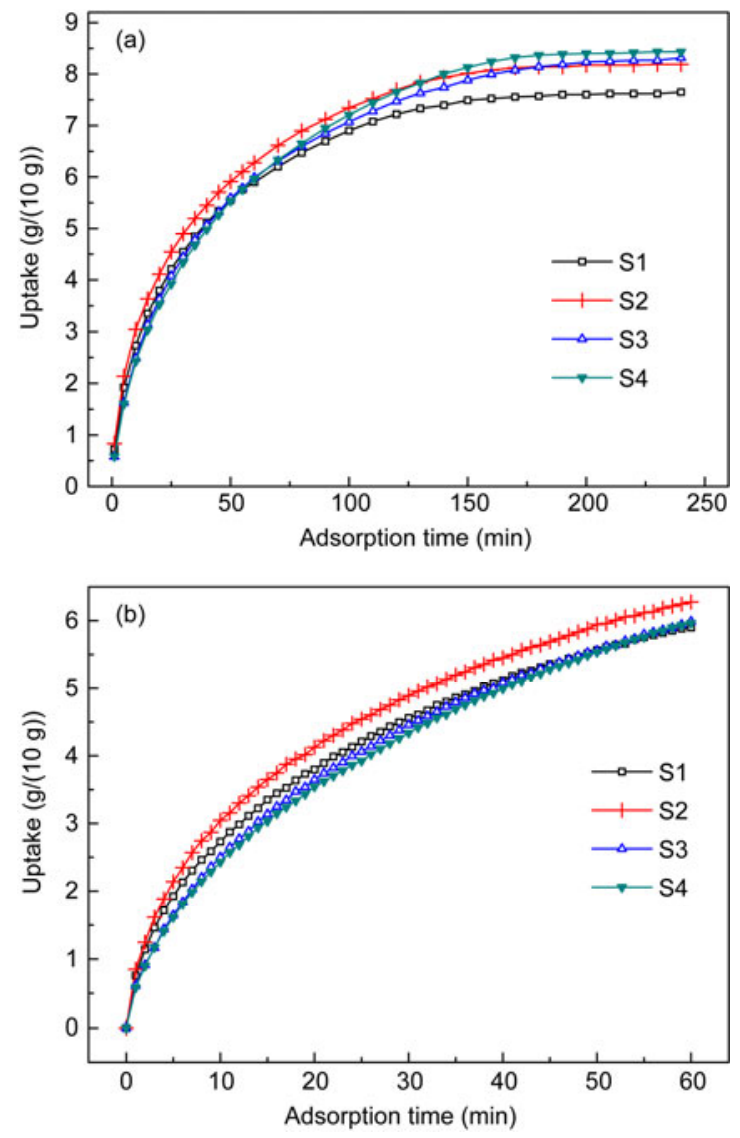

Figure 5 Ammonia adsorption on four samples. (a) Adsorption time of $4 \mathrm{~h}$; (b) adsorption time of $1 \mathrm{~h}$. 
the adsorption time of $1 \mathrm{~h}$, indicating that the sample is suitable for using in adsorption refrigeration.

The content and crystallinity of $\mathrm{CaCl}_{2}$ in sample $\mathrm{S} 2$ are greater than those in sample $\mathrm{S} 1$ and less than those in samples S3 and S4. The high content of $\mathrm{CaCl}_{2}$ in sample is advantageous to the ammonia adsorption. However, the increase of the crystallinity of $\mathrm{CaCl}_{2}$ in sample is disadvantageous to the ammonia adsorption. The synthetic effects of $\mathrm{CaCl}_{2}$ content and crystallinity lead to sample $\mathrm{S} 2$ to have the best adsorption performance within $1 \mathrm{~h}$. The analysis from Table 1, Figure 5(a) and (b) reveals that the rate of ammonia adsorption on the sample is a composite reflection of the content and crystallinity of $\mathrm{CaCl}_{2}$ in the sample. And the carbonization and activation temperature have an important effect on the content and crystallinity of $\mathrm{CaCl}_{2}$, adsorption amount and adsorption rate.

\subsection{Effect of the expanded graphite content on the adsorption performance}

Expanded graphite is added into the sample S2 to enhance the heat transfer. The thermal conductivity of adsorbents increases with the increase of the content of expanded graphite, as shown in Table 2. The thermal conductivity for sample $\mathrm{S} 2$ is $0.11 \mathrm{~W} \mathrm{~m}^{-1} \mathrm{~K}^{-1}$, while it increases to 0.28 $\mathrm{W} \mathrm{m}{ }^{-1} \mathrm{~K}^{-1}$ for sample S50 with the expanded graphite content of 50\%. Apparently from Figure 6(a), the adsorption amount at the adsorption time of $4 \mathrm{~h}$ decrease with the increase of the expanded graphite content due to the reduction of the content of $\mathrm{CaCl}_{2}$ in the samples. However, the samples exhibit different adsorption characteristic at the adsorption time less than $1 \mathrm{~h}$, as shown in Figure 6(b). The adsorption rates for samples $\mathrm{S} 10-\mathrm{S} 50$ are larger than that of sample S2 when adsorption time is less than $15 \mathrm{~min}$. If using the adsorption amount of per $\mathrm{kg} \mathrm{CaCl}_{2}$ as a standard for judging the adsorption performance, the rate of ammonia adsorption on the adsorbents increases with the increasing content of expanded graphite, especially at the beginning, as shown in Figure 6(c). The above analysis indicates that the addition of expanded graphite into the adsorbents can improve the heat transfer, leading to the increase of adsorption rate. However, the adding of expanded graphite reduces the content of $\mathrm{CaCl}_{2}$ in the adsorbent, which causes the reduction of adsorption capacity at the long adsorption time. So, it can be concluded that the adsorption capacity of ammonia on the adsorbent is a comprehensive reflection of the thermal conductivity and $\mathrm{CaCl}_{2}$ content in the adsorbent.

Figure 6(a)-(c) show that compared with sample S2, it takes a short time for samples S10-S50 to reach the adsorption

Table 2 Thermal conductivity of samples

\begin{tabular}{ccccccc}
\hline Sample & $\mathrm{S} 2$ & $\mathrm{~S} 10$ & $\mathrm{~S} 20$ & $\mathrm{~S} 30$ & $\mathrm{~S} 40$ & $\mathrm{~S} 50$ \\
\hline $\begin{array}{c}\text { Thermal conductivity } \\
\left(\mathrm{W} \mathrm{m} \mathrm{K}^{-1}\right)\end{array}$ & 0.11 & 0.13 & 0.16 & 0.19 & 0.21 & 0.28 \\
\hline
\end{tabular}
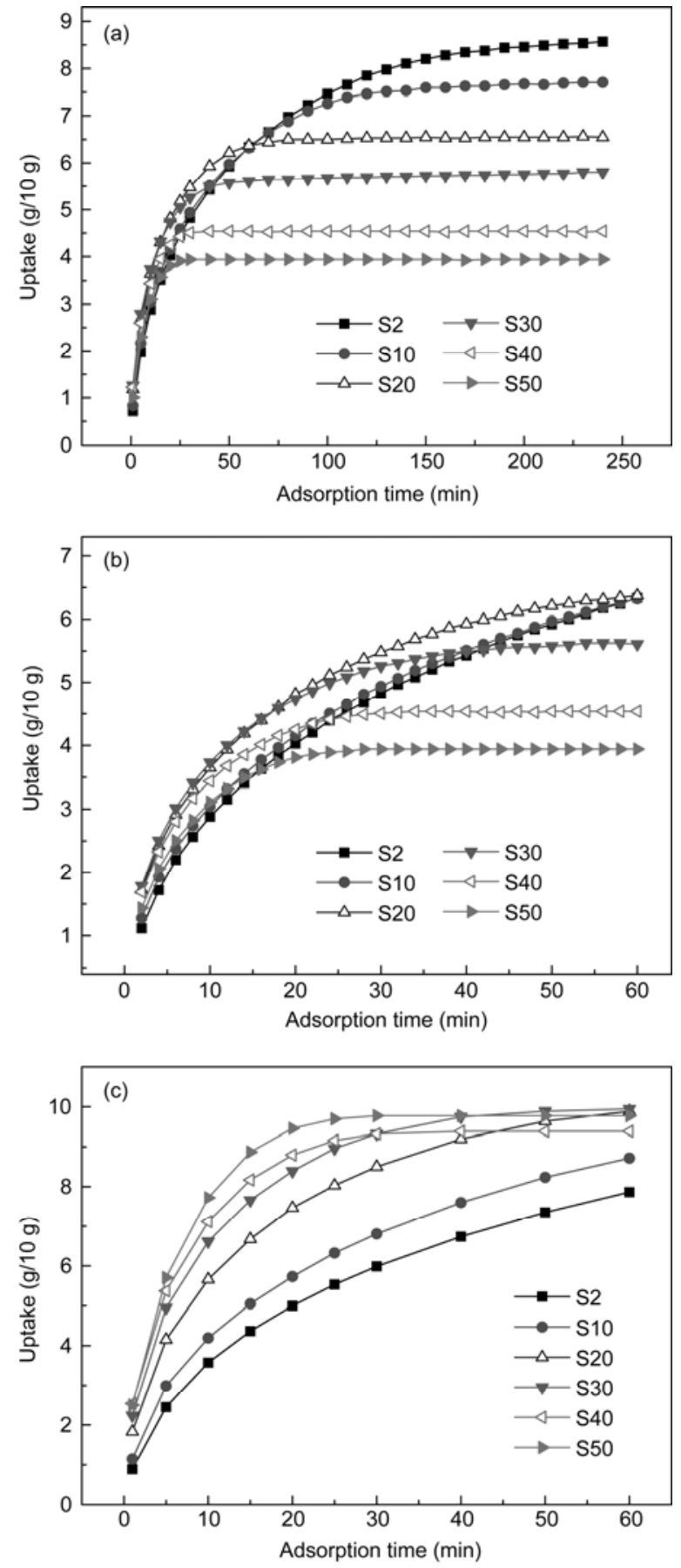

Figure 6 Effect of the expanded graphite content on the adsorption performance (a) with adsorption time of $4 \mathrm{~h}$; (b) with adsorption time of $1 \mathrm{~h}$; (c) using the adsorption amount per unit mass of $\mathrm{CaCl}_{2}$ as the standard for judging the adsorption performance.

equilibrium. Furthermore, the more the $\mathrm{CaCl}_{2}$ content is, the less time the sample needs to reach the adsorption equilibrium. For sample $S 2$, it takes almost $4 \mathrm{~h}$ to reach the adsorption equilibrium, while for sample S50, it takes only $25 \mathrm{~min}$.

It can be noticed from Figure 6(a)-(c) that compared with other samples, sample S30 has the best adsorption performance when the adsorption time is less than $20 \mathrm{~min}$, 
which adsorbs as high as 0.37 and $0.49 \mathrm{~g}$ ammonia per $\mathrm{g}$ adsorbent at the adsorption time of 10 and $20 \mathrm{~min}$, respectively, indicating a suitable application for adsorption refrigeration due to its short running cycle.

The above analysis indicates that the rate of ammonia adsorption on the adsorbent depends strongly on the content of expanded graphite and $\mathrm{CaCl}_{2}$ in the adsorbent. What is more, the addition of expanded graphite into the adsorbent can also solve the problem of swelling and agglomeration of $\mathrm{CaCl}_{2}$ during the process of ammonia adsorption due to the uniform dispersion of $\mathrm{CaCl}_{2}$ partly caused by addition of expanded graphite and the enough swelling spaces provided by expanded graphite.

\section{Conclusions}

To solve the contrast between enhanced heat transfer and enhanced mass transfer and develop a new adsorbent with high performance, fir sawdust and $\mathrm{CaCl}_{2}$ are selected as raw materials, and the carbonization and activation method are used for the preparation of a new adsorbent. The new adsorbent exhibits a high adsorption performance due to high porosity, uniform distribution and high content of $\mathrm{CaCl}_{2}$ and high thermal conductivity. The carbonization and activation temperature have an important effect on the content and crystallinity of $\mathrm{CaCl}_{2}$, adsorption amount and adsorption rate. The adsorbent prepared at the carbonization and activation temperature of $500^{\circ} \mathrm{C}$ has the best adsorption performance at the adsorption time less than $1 \mathrm{~h}$, indicating that the sample is suitable for using in adsorption refrigeration. The experimental results show that the addition of expanded graphite into the adsorbent can shorten the adsorption equilibrium time and the content of expanded graphite in the adsorbent has an important effect on the adsorption rate of ammonia. The adsorbent with the expanded graphite content of $30 \%$ has the best performance in terms of the adsorption refrigeration, which adsorbs ammonia as high as $0.37 \mathrm{~g} \mathrm{~g}^{-1}$ and has a specific cooling power (SCP) of $801.7 \mathrm{~W} \mathrm{~kg}^{-1}$ at the adsorption time of $10 \mathrm{~min}$. Besides, the problem of swelling and agglomeration of $\mathrm{CaCl}_{2}$ during the process of adsorption and desorption has been solved by using the composite adsorbent prepared by carbonizing and activating the mixture of $\mathrm{CaCl}_{2}$ and sawdust. Moreover, the concept of utilizing the sawdust and $\mathrm{CaCl}_{2}$ as raw materials for the preparation of adsorbents is of practical interest with respect to the potential quantity of biomass materials around the world, indicating that there would be a new market for biomass materials.

This work was supported by the Innovation Program of Chinese Academy of Sciences (y007y51001) and Comprehensive Strategic Cooperation Projects of
Chinese Academy of Sciences and Guangdong Province (2012B091100263).

1 Bidyut B S, Anutosh C, Shigeru K, et al. A new generation cooling device employing $\mathrm{CaCl}_{2}$-in-silica gel-water system. Int J Heat Mass Tran, 2009, 52: 516-524

2 Bao H S, Wang R Z, Wang L W. A resorption refrigerator driven by low grade thermal energy. Energ Convers Manage, 2010, 52: 2339-2344

3 Akahira A, Alam K C A, Hamamoto Y, et al. Experimental investigation of mass recovery adsorption refrigeration cycle. Int J Refrig, 2005, 28: 565-572

4 Maggio G, Gordeeva L G, Freni A, et al. Simulation of a solid sorption ice-maker based on the novel composite sorbent "lithium chloride in silica gel pores". Appl Therm Eng, 2009, 29: 1714-1720

5 Wang D C, Li Y H, Li D, et al. A review on adsorption refrigeration technology and adsorption deterioration in physical adsorption systems. Renew Sust Energ Rev, 2010, 14: 344-353

6 Ponomarenko I V, Glaznev I S, Gubar A V, et al. Synthesis and water sorption properties of a new composite " $\mathrm{CaCl}_{2}$ confined into SBA-15 pores”. Micropor Mesopor Mat, 2010,129: 243-250

7 Veselovskaya J V, Tokarev M M, Aristov Y I. Novel ammonia sorbents "porous matrix modified by active salt" for adsorptive heat transformation: 1. Barium chloride in various matrices. Appl Therm Eng, 2010, 30: 584-589

8 Gong L X, Wang R Z, Xia Z Z, et al. Design and performance prediction of a new generation adsorption chiller using composite adsorbent. Energ Convers Manage, 2011, 52: 2345-2350

9 Kiplagat J K, Wang R Z, Oliveira R G, et al. Lithium chloride-Expanded graphite composite sorbent for solar powered ice maker. Sol Energy, 2010, 84: 1587-1594

10 Zhong Y, Critoph R E, Thorpe R N, et al. Isothermal sorption characteristics of the $\mathrm{BaCl}_{2}-\mathrm{NH}_{3}$ pair in a vermiculite host matrix. Appl Therm Eng, 2007, 27: 2455-2462

$11 \mathrm{Li} \mathrm{S} \mathrm{L,} \mathrm{Xia} \mathrm{Z} \mathrm{Z,} \mathrm{Wu} \mathrm{J} \mathrm{Y,} \mathrm{et} \mathrm{al.} \mathrm{Experimental} \mathrm{study} \mathrm{of} \mathrm{a} \mathrm{novel}$ $\mathrm{CaCl}_{2}$ /expanded graphite- $\mathrm{NH}_{3}$ adsorption refrigerator. Int $\mathrm{J}$ Refrig, 2010, 33: 61-69

12 Veselovskaya J V, Critoph R E, Thorpe R N, et al. Novel ammonia sorbents "porous matrix modified by active salt" for adsorptive heat transformation: 3 . Testing of " $\mathrm{BaCl}_{2} /$ vermiculite" composite in a labscale adsorption chiller. Appl Therm Eng, 2010, 30: 1188-1192

13 Daou K, Wang R Z, Xia Z Z. Development of a new synthesized adsorbent for refrigeration and air conditioning applications. Appl Therm Eng, 2006, 26: 56-65

14 Gordeeva L G, Restuccia G, Freni A, et al. Water sorption on composites " $\mathrm{LiBr}$ in a porous carbon". Fuel Process Technol, 2002, 79: 225-231

15 Zhang X J, Qiu L M. Moisture transport and adsorption on silica gelcalcium chloride composite adsorbents. Energy Convers Manage, 2007, 48: 320-326

16 Gordeeva L G, Freni A, Krieger T A, et al. Composites "lithium halides in silica gel pores": Methanol sorption equilibrium. Micropor Mesopor Mat, 2008, 112: 254-261

17 Veselovskaya J V, Tokarev M M. Novel ammonia sorbents "porous matrix modified by active salt" for adsorptive heat transformation: 4 . Dynamics of quasi-isobaric ammonia sorption and desorption on $\mathrm{BaCl}_{2} /$ vermiculite. Appl Therm Eng, 2011, 31: 566-572

18 Zhu D S, Wu H J, Wang S W. Experimental study on composite silica gel supported $\mathrm{CaCl}_{2}$ sorbent for low grade heat storage. Int $\mathrm{J}$ Therm Sci, 2006, 45: 804-813

19 Chen H J, Cui Q, Tang Y, et al. Attapulgite based LiCl composite adsorbents for cooling and air conditioning applications. Appl Therm Eng, 2008, 28: 2187-2193

20 Yun C H, Park Y H, Park C R. Effects of pre-carbonization on porosity development of activated carbons from rice straw. Carbon, 2001, 39: $559-567$

Open Access This article is distributed under the terms of the Creative Commons Attribution License which permits any use, distribution, and reproduction in any medium, provided the original author(s) and source are credited. 